\title{
Long-term cognitive and behavioral consequences of neonatal encephalopathy following perinatal asphyxia: a review
}

\author{
Mariëlle van Handel • Hanna Swaab • \\ Linda S. de Vries • Marian J. Jongmans
}

Received: 22 November 2006 / Accepted: 1 February 2007 / Published online: 11 April 2007

(C) Springer-Verlag 2007

\begin{abstract}
Neonatal encephalopathy (NE) following perinatal asphyxia (PA) is considered an important cause of later neurodevelopmental impairment in infants born at term. This review discusses long-term consequences for general cognitive functioning, educational achievement, neuropsychological functioning and behavior. In all areas reviewed, the outcome of children with mild NE is consistently positive and the outcome of children with severe $\mathrm{NE}$ consistently negative. However, children with moderate NE form a more heterogeneous group with respect to outcome. On average, intelligence scores are below those of children with mild NE and age-matched peers, but within the normal range. With respect to educational achieve-
\end{abstract}

\footnotetext{
M. van Handel $(\bowtie)$

Department of Neonatology, University Medical Center Utrecht

(Wilhelmina Children's Hospital),

Heidelberglaan 1, 3584 CS Utrecht,

P.O. Box 85500, 3500 GA Utrecht, The Netherlands

e-mail: m.vanhandel@umcutrecht.nl

H. Swaab

Department of Clinical Child and Adolescent Studies,

Leiden University,

Wassenaarseweg 52 ,

2333 AK Leiden, The Netherlands

L. S. de Vries • M. J. Jongmans

Department of Neonatology, University Medical Center Utrecht

(Wilhelmina Children's Hospital),

Lundlaan 6,

3584 AE Utrecht, The Netherlands
}

M. J. Jongmans

Department of General and Special Education,

University of Utrecht,

Heidelberglaan 1,

3584 CS Utrecht, The Netherlands ment, difficulties have been found in the domains reading, spelling and arithmetic/mathematics. So far, studies of neuropsychological functioning have yielded ambiguous results in children with moderate NE. A few studies suggest elevated rates of hyperactivity in children with moderate NE and autism in children with moderate and severe NE. Conclusion: Behavioral monitoring is required for all children with NE. In addition, systematic, detailed neuropsychological examination is needed especially for children with moderate NE.

Keywords Asphyxia neonatorum · Hypoxia, brain . Hypoxia-ischemia, brain · Neuropsychology ·

Behavioral problems

$\begin{array}{ll}\text { Abbreviations } \\ \text { NE } & \text { neonatal encephalopathy } \\ \text { PA } & \text { perinatal asphyxia } \\ \text { HIE } & \text { hypoxic ischemic encephalopathy } \\ \text { ADHD } & \text { Attention deficit hyperactivity disorder } \\ \text { CP } & \text { cerebral palsy } \\ \text { EEG } & \text { electro encephalogram } \\ \text { MRI } & \text { magnetic resonance imaging } \\ \text { IQ } & \text { intelligence quotient }\end{array}$

\section{Introduction}

It has been widely accepted that severe NE following PA can lead to serious motor disabilities, mental retardation and seizure disorders [59]. Traditionally, research in this area has focused on developmental consequences at a very young age. In addition, the effects of NE have often been treated as an all-or-nothing phenomenon; patients have been believed to show a completely normal development or 
become severely disabled. So far, few studies have looked at milder consequences of $\mathrm{NE}$ at school age.

From perinatal asphyxia to neonatal encephalopathy

PA can be defined as impaired respiratory gas exchange accompanied by the development of acidosis [30]. The pathway of PA can have its onset in the antepartum, intrapartum or postpartum period. Estimates of the incidence of PA vary from 1 to 8 per 1,000 live births [4]. This wide range can be largely attributed to problems in selecting indicators to identify children with PA. As a consequence, researchers have used many different sets of inclusion criteria when studying the effects of PA. For this reason, it is difficult to compare results regarding developmental outcome of infants with PA across studies.

In the past, single-marker definitions were commonly used to diagnose infants with PA (e.g., low Apgar score). However, these single markers have relatively low sensitivity and specificity for accurate diagnosis [54]. Moreover, they lack predictive power [3, 20, 35-37, 40, 51]. Therefore, a shift has been made towards multiple-marker definitions based on combinations of indicators $[16,35]$. Among the perinatal indicators are fetal distress (abnormal heart rate or meconium-stained amniotic fluid), delay in onset of spontaneous respiration, low Apgar score $(<6$ or 7 at $5 \mathrm{~min}$ ), need for resuscitation and/or ventilation, and metabolic acidosis (cord $\mathrm{pH}<7.0$ or 7.1 and base deficit $>12 \mathrm{mmol} / \mathrm{l}$ ). Postnatal indicators of PA include NE, multiorgan failure and abnormal findings on brain imaging. Of the above, the concept of NE is generally accepted as an essential criterion for the diagnosis of PA $[4,30]$. NE has been defined as a clinical syndrome of disturbed neurological function in the earliest days of life in term infants, manifested by difficulty with initiating and maintaining respiration, depression of tone and reflexes, subnormal level of consciousness and often by seizures [30].

Recent studies of the protective effects of head cooling and systemic hypothermia after NE following PA used a combination of clinical and physiological criteria of PA (including a pH of 7.0 or less or a base deficit of $16 \mathrm{mmol}$ per liter or more) and a neurological examination to determine the severity of NE [22, 52]. These inclusion criteria are closely related to a set of criteria postulated by The American College of Obstetricians and Gynecologists (ACOG). There has been extensive debate about the relationships between PA, NE and serious possible consequences such as CP [25]. Contrary to what was once believed, only a small part of all cases of $\mathrm{CP}$ are caused by intrapartum events [10]. Likewise, many cases of NE are not associated with a history of PA $[6,38]$. However, NE has to be present in the pathway from PA to subsequent $\mathrm{CP}$ [25]. The ACOG and the International Cerebral Palsy Task
Force proposed a set of criteria to define an acute intrapartum hypoxic event that could subsequently lead to $\mathrm{CP}[4,30]$. The presence of moderate or severe NE and metabolic acidosis $(\mathrm{pH}<7$ and base deficit $\geq 12 \mathrm{mmol} / \mathrm{l})$ are considered to be essential markers for hypoxic ischemic injury. In addition, these criteria underline the importance of excluding other identifiable causes of NE before assuming asphyxia as the underlying etiology.

Both in clinical practice and for scientific purposes, patients suffering from NE are often assigned an encephalopathy score. Several classification systems can be identified. Leviton and Nelson provide an overview of qualitative and quantitative grading schemes [27]. In addition, scoring systems were developed that are applicable in low-income settings. Moreover, a new grading system has gained interest in the literature [19, 33]. The classification system of Sarnat and Sarnat developed in 1976 [50] is still widely used and the basis for most modern classification systems. In this review, the Sarnat system is used to grade NE because in most studies that were included this system it had been applied. According to the Sarnat system children are assigned a score of 1,2 or $3(1=$ mild NE; $2=$ moderate NE; $3=$ severe NE). Stage 1 lasts less than $24 \mathrm{~h}$ and is characterized by hyperalertness, uninhibited Moro and stretch reflexes, sympathetic effects and a normal EEG. Stage 2 is marked by obtundation, hypotonia, strong distal flexion and multifocal seizures. Infants with the most severe stage of NE (stage 3) are stuporous and flaccid, and brain stem and autonomic functions are suppressed. In addition, the EEG shows abnormal patterns of brain activity.

Grades of neonatal encephalopathy in relation to developmental outcome

Encephalopathy scores have often been used to predict neurodevelopmental outcome [43, 44, 46]. Although strong relationships exist between the categories of $\mathrm{NE}$ and developmental outcome, diversity of outcome is reported within individual grades [41]. This diversity may be partly explained by individual researchers using different neurological signs for category inclusion [27]. The Sarnat grading system has helped to clarify the NE categories and improved their usefulness in studies of prognosis [45].

Most outcome studies have focused on neurological functioning and severe deficits in young children ( $<4$ years). In general, very few children with mild encephalopathy show neurological impairments or have developed severe mental or motor retardation at preschool age. In contrast, children with severe encephalopathy nearly always die or develop severe impairments such as $\mathrm{CP}$, mental retardation, epilepsy and in some cases sensorineural hearing loss or cortical visual impairment $[4,45,47]$. While dyskinetic CP 
or quadriplegia is more commonly seen following "acute near total type of asphyxia" with MRI abnormalities present in the deep grey nuclei and in the perirolandic cortex, milder forms of $\mathrm{CP}$, such as spastic diplegia, are more common among those with "subacute partial asphyxia" with MRI abnormalities in the watershed areas. Hemiplegia can be seen following "perinatal arterial stroke." Although this condition will present with NE and seizures, it is less commonly associated with PA $[13,34]$. Children who have suffered moderate encephalopathy seem to form a more heterogeneous group; research shows varying rates of infant death and morbidity [16].

\section{Need for long-term follow-up and focus on cognitive and behavioral outcomes}

Because the majority of studies have focused on detecting major developmental abnormalities at a very young age, still little is known about the milder difficulties children may experience in the long run. Recently, however, research has started to focus more on the subtle problems of children without major neurological deficits [8, 23, 32, 35, 43, 44, 46]. Knowledge of the outcome for this group of children is important because these subtle problems can affect later scholastic achievement and behavioral adjustment.

Cognitive and behavioral difficulties can be expected because of the patterns of brain injury that have been associated with NE. The hippocampus and striatum are among the brain structures that can be affected [7, 21, 31, $42,56]$. These structures have been associated with specific cognitive functions such as memory and attention and hypothesized to play a role in the pathogenesis of ADHD, autism and schizophrenia [14-16, 28, 57].

To gain insight into the long-term effects of $\mathrm{NE}$ on development, follow-up is required throughout the schoolage period. Specific cognitive functions continue to develop throughout childhood. As it is impossible to examine a function that has not developed yet, short-term follow-up cannot exclude minor cognitive and behavioral difficulties at school age. Moreover, subtle functional deficits usually do not become apparent until a child faces increasing demands to master complex abilities in school.

The aim of this review was to discuss the results of previously published studies on the possible effects of $\mathrm{NE}$ on general cognitive functioning, educational achievement, neuropsychological functioning and behavior from infancy through adolescence. A literature search was performed using Web of Science. Studies were screened that had been published before October 2006. Search terms were 'asphyxia neonatorum,' 'neonatal encephalopathy,' 'newborn encephalopathy,' 'hypoxic-ischemic encephalopathy' and 'perinatal asphyxia' combined with the terms 'cognition/ cognitive' and 'behavior(-al)'. Reference lists of retrieved articles were screened for additional relevant publications. Studies were selected that reported the developmental outcome of NE or HIE following PA of children until the age of 18 years. The presence of $\mathrm{NE}$ was required for selection. When no additional indicators of PA were used, the asphyxial etiology of the NE had to be assumed by the authors. Studies were excluded when NE was partially caused by other conditions than PA, for example [17, 34]. Also, studies were excluded in which outcome was presented in preset categories (e.g., normal versus abnormal), in which several outcome measures were combined, for example $[11,18,26]$. In these cases it was not possible to judge whether a child had been assigned to the category 'abnormal' because of cognitive or behavioral problems or because of other problems, e.g., motor difficulties. A third reason for excluding studies from this review was the selection of children from a larger group of eligible patients. For example, some researchers selected only those children with abnormal findings on MRI in order to examine the correlation with outcome [61]. In this review, outcome is reported according to grade of NE (mild, moderate or severe). Most authors of the included studies used the classification system of Sarnat when determining the severity of the NE. However, in three cases the authors significantly deviated from this system [32, 47, 53]. In order to increase comparability across studies, the patients in these studies were reclassified according to Sarnat criteria. Articles were reviewed that reported general intellectual ability, levels of specific cognitive functions and/or behavioral problems. Details of the samples, inclusion criteria, outcome measures and results are described in Tables 1, 2, 3, 4, 5, 6, 7 and 8 .

\section{General cognitive development}

Infancy (0-24 months)

Eight studies were identified that measured developmental levels between the ages of 12 and 24 months in children with NE [2, 9, 12, 24, 39, 49, 50, 55]. Two of these were performed in low-income, non-western countries [2, 55]. Standardized testing with the Griffiths Mental Development Scales showed that almost all children with moderate NE who had been diagnosed to have CP at the age of 12 months were severely developmentally delayed (Table 1). In these studies, the rates of $\mathrm{CP}$ among children with moderate NE varied between 23\% [24] and 82\% [49]. Children with moderate NE without $\mathrm{CP}$ at this age performed in the average range or above, although the range of scores varies widely across studies. In addition, other studies in which the Denver Developmental Screening Test or the Bayley Scales 
Table 1 Griffiths Mental Development Scale* at 1 year

\begin{tabular}{|c|c|c|}
\hline & $\mathrm{CP}$ & No $\mathrm{CP}$ \\
\hline Carli et al. (2004) [12] & $\begin{array}{l}\text { Moderate } \mathrm{NE}, \mathrm{N}=13 \\
\cdot \mathrm{N}=10:<-2 \mathrm{SD} \\
\cdot \mathrm{N}=1: \text { between }-2 \mathrm{SD} \text { and }-1 \mathrm{SD} \\
\cdot \mathrm{N}=1:>-1 \mathrm{SD} \\
\cdot \mathrm{N}=1: \text { untestable }\end{array}$ & $\begin{array}{l}\text { Moderate } \mathrm{NE}, \mathrm{N}=27 \\
\cdot \mathrm{N}=4 \text { : between }-2 \mathrm{SD} \text { and }-1 \mathrm{SD} \\
\cdot \mathrm{N}=23 \text { : }>-1 \mathrm{SD}\end{array}$ \\
\hline Gray et al. (1993) [24] & $\begin{array}{l}\text { Moderate NE, } \mathrm{N}=10 \\
\cdot \mathrm{N}=9:<55 \\
\cdot \mathrm{N}=1: 87\end{array}$ & $\begin{array}{l}\text { Moderate NE, } \mathrm{N}=9 \\
\text { Mean }=118(\mathrm{~N}=1 \text { not assessed })\end{array}$ \\
\hline Thompson et al. (1997) [55] & $\begin{array}{l}\text { No grades of NE recorded, } N=16 \\
\text { Mean }=47 \text {, range: } 7-101\end{array}$ & $\begin{array}{l}\text { No grades of NE recorded, } N=24 \\
\text { Mean }=16 \text {, range } 94-128\end{array}$ \\
\hline Barnett et al. (2004) [9] & & $\begin{array}{l}\text { No grades of NE recorded, } \mathrm{N}=59 \\
\text { Mean }=100.34, \mathrm{SD}=15.05 \text {, range: } 55-130\end{array}$ \\
\hline Rutherford et al. (1996) [49] & $\begin{array}{l}\text { Moderate } \mathrm{NE}, \mathrm{N}=8 \\
\text { All below normal (cut-off point not reported) } \\
\text { Severe } \mathrm{NE}, \mathrm{N}=1 \\
\text { Below normal }\end{array}$ & $\begin{array}{l}\text { Mild NE, } \mathrm{N}=4 \\
\text { All normal }\end{array}$ \\
\hline
\end{tabular}

${ }^{*}$ Griffiths mean of standardization sample $=100.18, \mathrm{SD}=12.76$

of Infant Development were used reported normal development in children with mild NE, none of whom had CP.

Two to six years, without $\mathrm{CP}$

In all of the selected studies [8, 9, 43, 44, 53], children with mild NE showed average general intellectual abilities that equaled those of a healthy comparison group (Table 2). Although children with moderate NE also performed in the average range, their abilities were significantly below those of children with mild NE and a reference group. The general intellectual abilities of children with severe NE were assessed in only one study. These children showed very low levels of functioning: a mean IQ of 37.1 was

Table 2 IQ at 2-6 years (no CP)

\begin{tabular}{|c|c|c|c|c|}
\hline & Age (years) & $\begin{array}{l}\text { Mild } \\
\text { NE }\end{array}$ & $\begin{array}{l}\text { Moderate } \\
\mathrm{NE}\end{array}$ & $\begin{array}{l}\text { Severe } \\
\mathrm{NE}\end{array}$ \\
\hline $\begin{array}{l}\text { Barnett et al. } \\
(2004)^{\mathrm{b}}[9]\end{array}$ & 2 & \multicolumn{3}{|c|}{$\mathrm{N}=45,{ }^{\mathrm{f}}$ Griffiths: mean $=103.53, \mathrm{SD}=12.33$ (range: $81-140$ ) } \\
\hline $\begin{array}{l}\text { Robertson \& Finer } \\
\quad(1985)^{\mathrm{a}}[43]\end{array}$ & 3.5 & $\begin{array}{l}\mathrm{N}=66, \text { Stanford-Binet: } \\
\text { mean } \mathrm{IQ}=101.5, \mathrm{SD}=14.0\end{array}$ & $\begin{array}{l}\mathrm{N}=94\left(21.3 \% \text { handicapped }^{2}\right) \\
\text { Stanford-Binet }{ }^{2}: \text { mean } \\
\mathrm{IQ}=92.3, \mathrm{SD}=23.2\end{array}$ & $\begin{array}{l}\mathrm{N}=7 \text {, Stanford-Binet } \\
\quad \text { mean } \mathrm{IQ}=37.1 \\
\mathrm{SD}=26.7\end{array}$ \\
\hline $\begin{array}{l}\text { Shankaran } \\
\qquad(1991)^{\mathrm{cb}}[53]\end{array}$ & 5 & \multicolumn{3}{|c|}{$\mathrm{N}=14,{ }^{\mathrm{f}}$ McCarthy: $64 \%:>-1 \mathrm{SD}, 86 \%:>-2 \mathrm{SD}$} \\
\hline $\begin{array}{l}\text { Barnett et al. } \\
(2002)^{\text {bd }}[8]\end{array}$ & $5.5-6.5$ & $\begin{array}{l}\mathrm{N}=20, \text { WPPSI-R: mean IQ }=109.7 \\
\quad \mathrm{SD}=14.6(\mathrm{~N}=1: 76, \text { rest: }>90)\end{array}$ & $\begin{array}{l}\mathrm{N}=12 \text {, WPPSI-R: }(\mathrm{N}=1: \text { untestable }) \\
\quad \mathrm{N}=11: \text { mean IQ }=106.2 \\
\mathrm{SD}=11.8(\mathrm{~N}=1: 84, \text { rest: }>94)\end{array}$ & \\
\hline $\begin{array}{l}\text { Barnett et al. } \\
\qquad(2004)^{\mathrm{b}}[9]\end{array}$ & $5-6$ & \multicolumn{3}{|c|}{$\mathrm{N}=53,{ }^{\mathrm{f}}$ WPPSI-R $85 \%:>-1 \mathrm{SD}$, mean IQ $=101.98, \mathrm{SD}=16.06$, range: $69-139$} \\
\hline $\begin{array}{l}\text { Robertson \& Finer } \\
\qquad(1988)^{\mathrm{e}}[44]\end{array}$ & 5.5 & $\begin{array}{l}\mathrm{N}=56, \text { Stanford-Binet: } \\
\quad \text { mean } \mathrm{IQ}=106, \mathrm{SD}=12\end{array}$ & $\begin{array}{l}\mathrm{N}=71 \text {, Stanford-Binet: mean } \\
\mathrm{IQ}=99, \mathrm{SD}=18)\end{array}$ & \\
\hline
\end{tabular}

Griffiths Mental Developmental Scales: mean of standardization sample $=100.18, \mathrm{SD}=12.76$; Stanford-Binet Intelligence Scales: mean of standardization sample $=100, \mathrm{SD}=16$; McCarthy Scales of Children's Abilities: mean of standardization sample $=100, \mathrm{SD}=16$; Wechsler Preschool and Primary Scale of Intelligence-revised: mean of standardization sample $=100, \mathrm{SD}=15 .{ }^{\mathrm{a}}$ All groups are significantly different from the other groups; $\mathrm{p}=0.001{ }^{\mathrm{b}}$ No significance tests performed. ${ }^{\mathrm{c}}$ Patients were reclassified by author $(\mathrm{MH})$ according to the classification system of Sarnat [50]. ${ }^{\mathrm{d}}$ In the original article, results are presented for individual cases. Group means and standard deviations have been calculated by one of the authors (MH). ${ }^{\mathrm{e}}$ Mild NE not significantly below comparison group; moderate NE significantly below mild NE and comparison group.

${ }^{\mathrm{f}}$ Combined group of mild, moderate and severe NE 
Table 3 IQ at $7-9$ years (no CP)

\begin{tabular}{|c|c|c|c|c|}
\hline & $\begin{array}{l}\text { Age } \\
\text { (years) }\end{array}$ & Mild NE & Moderate NE & Severe NE \\
\hline Marlow $(2005)^{\mathrm{b}}[32]$ & 7 & & $\begin{array}{l}\mathrm{N}=65 \text {, BAS-II: } \\
\text { Group } 1(\mathrm{~N}=34): \mathrm{GCS}=112.3 \text {, } \\
\mathrm{SD}=11.2 \\
\text { Group } 2^{\mathrm{d}}(\mathrm{N}=31): \mathrm{GCS}=102.7 \\
\mathrm{SD}=13.2\end{array}$ & \\
\hline $\begin{array}{l}\text { Robertson et al. }(1989)^{\mathrm{a}} \\
\text { [46] }\end{array}$ & 8 & $\begin{array}{l}\mathrm{N}=56 \text {, WISC-R: mean IQ }=106 \\
\mathrm{SD}=13\end{array}$ & $\begin{array}{l}\mathrm{N}=66, \text { WISC-R: } \text { mean IQ }=102 \\
\mathrm{SD}=17\end{array}$ & $\begin{array}{l}\mathrm{N}=5 \text {, WISC-R: mean IQ }=36, \\
\mathrm{SD}=7\end{array}$ \\
\hline Robertson $(1997)^{\mathrm{c}}$ [47] & 9 & & $\begin{array}{l}\mathrm{N}=64, \text { WISC-R: mean IQ }=100 \\
\mathrm{SD}=14\end{array}$ & \\
\hline
\end{tabular}

WISC-R: Wechsler Intelligence Scale for Children-revised: mean of standardization sample $=100, \mathrm{SD}=15$; BAS-II: British Ability Scales, GCS: General Cognitive Score: mean of standardization sample $=100, \mathrm{SD}=15$. ${ }^{\mathrm{a}}$ IQ of mild NE is not significantly lower than IQ of comparison group. IQ of moderate and severe NE is significantly lower than IQ of mild NE and comparison group $(\mathrm{p}<0.001)$. ${ }^{\mathrm{b}}$ GSC of group 1 is not significantly lower than GSC of comparison group. GCS of group 2 is significantly lower than GCS of comparison group ( $\mathrm{p}<0.01)$. ${ }^{\mathrm{c}}$ Mean IQ is significantly lower than IQ of comparison group. ${ }^{\mathrm{d}}$ Marlow refers to this group as 'severe NE.' This group is reclassified by one fo the authors (MH) according to the classification system of Sarnat [50]

found [43]. In two studies, no grades of NE were recorded $[9,53]$, which hampers interpretation of these data. Rates of average or above-average functioning were $85 \%$ and $64 \%$, respectively.

Seven to nine years, without $\mathrm{CP}$

At school age, children with mild NE showed age-appropriate levels of general intellectual ability and performed as well as healthy comprison children on standardized testing [32, 46, 47] (Table 3). Although most children with moderate NE obtained significantly lower scores on intelligence measures than children with mild NE and comparison groups, their ability levels were in the average range.

\section{Educational achievement}

Relative strengths and weaknesses in cognitive functioning can become visible when children have to acquire specific scholastic abilities in school. A test of school readiness showed that 5.5-year-old children with mild and moderate NE were not significantly behind compared to comparison children [24]. However, children with moderate NE achieved lower scores in all domains, and $42 \%$ of them scored more than 1 SD below the average of the standardization group. Children with severe NE showed low school readiness scores at the age of 5.5 years. Table 4 gives an overview of the results of four studies, which assessed reading, writing, spelling and mathematics/arithmetic in school-aged children [32, 35, $46,47]$. Survivors of mild NE compared to a comparison group were not significantly more often more than one grade behind in reading, spelling and arithmetic. In these domains, all children with severe NE were more than one grade behind the expected level for their age. The group with moderate NE appeared to have distinct difficulties in reading, spelling and arithmetic/mathematics. Writing has been found to be less developed in only one subgroup of one of the studies.

\section{Neuropsychological functions}

Studies of specific neuropsychological functions yielded results that are similar to the findings on general intellectual ability and educational achievement (Tables 5 , 6, 7 and 8). Children who suffered from mild NE tended to show normal receptive vocabulary and visual-motor integration at $3.5,5.5$ and 8 years of age $[43,44,46]$. As is the case in other cognitive domains, the severe group was impaired, and their ability levels were below those of children with mild or moderate NE and comparison groups. The moderate group showed an ambiguous pattern of performance. Deficits were found in receptive vocabulary, language and visual-motor integration. In contrast, attention and executive functions, visuospatial ability, and memory and learning were normal in a subgroup of 7-year-old children [29]. Although memory and learning did not seem to be impaired in this subgroup, these children had difficulties in the subdomains narrative memory and sentence repetition, compared to intact memory for faces, names, everyday events and intact orientation. In addition, auditory verbal learning and delayed recall was impaired in a group of 9and a group of 16-year-old children with moderate NE $[31,47]$. Tests of other auditory skills in the former showed intact auditory attention and concentration, 
Table 4 Scholastic abilities at $7-13$ years (no CP)

\begin{tabular}{|c|c|c|c|c|}
\hline & & Mild NE & Moderate NE & Severe NE \\
\hline \multirow[t]{5}{*}{ Reading } & Robertson \& Finer (1989) [46] & \multirow[t]{4}{*}{$\begin{array}{c}13 \%>1 \text { grade level below } \\
\text { expected level for age }\end{array}$} & $\begin{array}{c}35 \%>1 \text { grade level below } \\
\text { expected level for age }^{\mathrm{a}}\end{array}$ & \multirow[t]{4}{*}{$\begin{array}{c}100 \%>1 \text { grade level below } \\
\text { expected level for age }\end{array}$} \\
\hline & Robertson (1997) [47] & & $\begin{array}{l}41 \%>1 \text { grade level below } \\
\text { expected level for age }\end{array}$ & \\
\hline & Marlow et al. (2005) [32] & & Group 1: < control group ${ }^{\mathrm{c}}$ & \\
\hline & & & Group $2^{\text {f: }}<$ control group $^{\mathrm{d}}$ & \\
\hline & Moster et al. (2002) [35] & \multirow[t]{2}{*}{$\mathrm{NE}<$ control group $^{\mathrm{d}}$} & 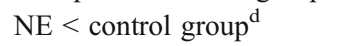 & \multirow[t]{2}{*}{$\mathrm{NE}<$ control group $^{\mathrm{d}}$} \\
\hline \multirow[t]{2}{*}{ Writing } & Marlow et al. (2005) [32] & & $\begin{array}{l}\text { Group 1: = control group } \\
\text { Group } 2^{\text {f: }}<\text { control group }^{\mathrm{e}}\end{array}$ & \\
\hline & Moster et al. (2002) [35] & $\mathrm{NE}=$ control group & $\mathrm{NE}=$ control group & $\mathrm{NE}=$ control group \\
\hline \multirow[t]{4}{*}{ Spelling } & Robertson \& Finer (1989) [46] & \multirow[t]{3}{*}{$\begin{array}{c}2 \%>1 \text { grade level below } \\
\text { expected level for age }\end{array}$} & $\begin{array}{l}18 \%>1 \text { grade level below } \\
\text { expected level for age }\end{array}$ & \multirow[t]{3}{*}{$\begin{array}{c}100 \%>1 \text { grade level below } \\
\text { expected level for age }\end{array}$} \\
\hline & Marlow et al. (2005) [32] & & Group 1: < control group ${ }^{c}$ & \\
\hline & & & Group $2^{\text {f }}:<$ control group $^{\mathrm{d}}$ & \\
\hline & Moster et al. (2002) [35] & $\mathrm{NE}=$ control group & $\mathrm{NE}=$ control group & $\mathrm{NE}=$ control group \\
\hline \multirow[t]{5}{*}{ Math } & Robertson \& Finer (1989) [46] & \multirow[t]{4}{*}{$\begin{array}{c}16 \%>1 \text { grade level below } \\
\text { expected level for age }\end{array}$} & $\begin{array}{l}20 \%>1 \text { grade level below } \\
\text { expected level for age }{ }^{\mathrm{a}}\end{array}$ & \multirow[t]{4}{*}{$\begin{array}{c}100 \%>1 \text { grade level below } \\
\text { expected level for age }{ }^{b}\end{array}$} \\
\hline & Robertson (1997) [47] & & $\begin{array}{l}39 \%>1 \text { grade level below } \\
\text { expected level for age }\end{array}$ & \\
\hline & Marlow et al. (2005) [32] & & Group 1: = control group & \\
\hline & & & Group $2^{\text {f: }}<$ control group $^{\mathrm{d}}$ & \\
\hline & Moster et al. (2002) [35] & $\mathrm{NE}<$ control group $^{\mathrm{c}}$ & $\mathrm{NE}<$ control group $^{\mathrm{c}}$ & $\mathrm{NE}<$ control group $^{\mathrm{c}}$ \\
\hline
\end{tabular}

Robertson \& Finer (1989) [46]: age 8 years; Marlow et al. (2005) [32]: age 7 years; Moster et al. (2002) [35]: age 8-13 years

${ }^{\mathrm{a}}$ Significant difference with mild NE and comparison group, $\mathrm{p}<0.01 ;{ }^{\mathrm{b}}$ statistical analyses are not given because of small group and low scores;

${ }^{\mathrm{c}}$ significant difference with comparison group, $\mathrm{p}<0.05$; ${ }^{\mathrm{d}}$ significant difference with comparison group, $\mathrm{p}<0.001$; ${ }^{\mathrm{e}}$ significant difference with comparison group, $\mathrm{p}<0.01 ;{ }^{\mathrm{f}}$ Marlow refers to this group as 'severe NE'. This group is reclassified by one of the authors (MH) according to the classification system of Sarnat [50]

language and binaural separation, in contrast to impaired binaural integration, and sequencing and labeling [47].

\section{Behavioral problems}

So far, few researchers have addressed the issue of behavioral problems in children with a history of NE. Four studies were identified that met the selection criteria. In general, hyperactivity was more often present in children with moderate NE, but not in children with mild NE [32, 35, 44]. In addition, one study that used parent's observations of their child's behavior found more problems related to tractability, aggression, passivity and anxiety in a mixed group of children with NE compared to a control group [35]. No differences were found, however, related to attention, habituation and impulsivity. A recent study reported an unexpectedly high proportion of children with moderate and severe NE that developed an autism spectrum disorder [5]. However, the inclusion criteria differed considerably from those of Sarnat. Both groups can be classified as moderate NE when Sarnat's criteria are applied. In addition, the authors explicitly did not exclude etiologies of NE other than PA.

\section{Discussion and conclusion}

In the introduction section of this review, problems were mentioned with regard to the comparability of different outcome studies of NE. Even after careful selection on the basis of predetermined criteria, comparing studies remained difficult. The main reason for this was the way test results were presented. In many cases, outcome of the children was reported in two or more categories, e.g., normal/mildly delayed/abnormal. One of the problems that arise due to such categorization, is the subjectivity involved in determining the cut-off points of the categories. Often, these cutoff points seemed to be chosen arbitrarily or not justified at all. Another issue that adds to this problem is the use of different tests of development, cognitive ability or behavioral problems. One can hardly compare, for example, the proportions of children with developmental delay in two studies when these are represented by a score below 85 on the Bayley Scales of Infant Development in one of the studies and by a score below 70 on the Griffiths Mental Developmental Scales in the other. To enable readers to compare studies, results of significance testing between subgroups of children with $\mathrm{NE}$ and comparison groups were added to the tables whenever available. 
Table 5 Neuropsychological functions [43, 44, 46]

\begin{tabular}{|c|c|c|c|}
\hline Tests & 3.5 years & 5.5 years & 8 years \\
\hline \multirow[t]{3}{*}{$\begin{array}{l}\text { Receptive } \\
\text { vocabulary }\end{array}$} & $\begin{array}{l}\text { Mild NE: in the mean } \\
\text { range }\end{array}$ & Mild NE = control group & Mild NE = control group \\
\hline & Moderate $\mathrm{NE}<$ mild $\mathrm{NE}^{\mathrm{a}}$ & $\begin{array}{l}\text { Moderate } \mathrm{NE}<\text { mild NE }+ \\
\text { control group }^{\mathrm{b}}\end{array}$ & Moderate $\mathrm{NE}<$ mild NE + control group ${ }^{\mathrm{a}}$ \\
\hline & $\begin{array}{l}\text { Severe } \mathrm{NE}<\text { mild }+ \\
\text { moderate } \mathrm{NE}^{\mathrm{a}}\end{array}$ & Severe NE: $100 \%<-1 \mathrm{SD}^{\mathrm{c}}$ & Severe $\mathrm{NE}<$ mild $\mathrm{NE}+$ control group $^{\mathrm{c}}$ \\
\hline \multirow[t]{3}{*}{$\begin{array}{l}\text { Visual- motor } \\
\text { integration }\end{array}$} & $\begin{array}{l}\text { Mild NE: in the mean } \\
\text { range }\end{array}$ & Mild NE = control group & Mild NE = control group \\
\hline & Moderate $\mathrm{NE}<$ mild $\mathrm{NE}^{\mathrm{a}}$ & $\begin{array}{l}\text { Moderate } \mathrm{NE}<\text { mild } \mathrm{NE}+ \\
\text { control group }^{\mathrm{a}}\end{array}$ & \multirow[t]{2}{*}{$\begin{array}{l}\text { Moderate } \mathrm{NE}<\text { mild } \mathrm{NE}+\text { control group }{ }^{\mathrm{a}} \text { Severe } \mathrm{NE}<\text { mild NE } \\
+ \text { control group }^{\mathrm{c}}\end{array}$} \\
\hline & $\begin{array}{l}\text { Severe } \mathrm{NE}<\text { mild }+ \\
\text { moderate } \mathrm{NE}^{\mathrm{a}}\end{array}$ & Severe NE: $100 \%<-1 \mathrm{SD}^{\mathrm{c}}$ & \\
\hline
\end{tabular}

Receptive vocabulary: Peabody Picture Vocabulary Test, visual-motor integration: Developmental Test of Visual-Motor Integration. ${ }^{a} \mathrm{p}<0.001$; ${ }^{\mathrm{b}} \mathrm{p}<0.01 ;{ }^{\mathrm{c}}$ statistical analyses are not given because of small group and low scores

Children with a history of NE who suffer from $\mathrm{CP}$ at the age of 12 months are often also severely developmentally delayed. Estimates vary between $77 \%$ [12] and 90\% [24]. Of the children without $\mathrm{CP}$, those with mild NE have an excellent prognosis. Their intelligence, educational achievement and neuropsychological functions are comparable to healthy peers at least until middle childhood.

Children with severe NE appear to be impaired in every cognitive domain. They are less intelligent and perform worse at school and at neuropsychological tests than both healthy controls and children with mild or moderate NE.

As was expected, the children with moderate NE seem to form the most heterogeneous group. In general, these children are significantly less intelligent than children with mild NE and healthy peers, but their scores are still in the average range. And although these children are equally ready to go to school as other children at the age of 5.5 years, when measured in middle childhood, they perform less well in the domains reading, spelling and mathematics. On the basis of these results, it is possible that children with moderate NE fall behind in school, but do not show clear deficits at standardized testing. Another issue is raised by the relatively broad range of performance of children with moderate NE. Calculating mean IQ scores masks individual differences, which are large in groups of children with moderate NE. Therefore, means do not describe this group well, and it would be more informative to look at the distribution of scores. The description of neuropsychological functions in this review is based on six studies, in which five different tests were used in five different samples of children with moderate NE. These studies do not provide sufficient and comparable data to draw reliable conclusions about patterns of neuropsychological strengths and difficulties. The heterogeneous nature of the group of children with moderate NE raises the question whether these children really form one group. Marlow et al. [32] divided a group of children with moderate NE according to the severity of the symptoms of the NE. The group with the least severe neonatal symptoms showed a few discrete neuropsychological difficulties, but was more intelligent and performed better in school than the group with the most severe neonatal symptoms. Marlow suggested a dose-response effect of hypoxia within this group with moderate NE. This idea of a continuum of casualty with regard to morbidity has already been proposed by Low [29]. He suggested a theory of a critical threshold of asphyxia beyond which brain damage occurs. Beyond this threshold, a spectrum of minor and major deficits would occur. So, although the classification system of Sarnat [50] appears to be very useful for the

Table 6 Neuropsychological functions (NEPSY): moderate NE compared to control group [32]

\begin{tabular}{lll}
\hline Age: 7 years & Moderate NE group 1 & Moderate NE group 2* \\
\hline Attention and executive & Group $1=$ control group $(\mathrm{p}=0.08)$ & Group 2< control group $(\mathrm{p}<0.01)$ \\
Language & Group $1<$ control group $(\mathrm{p}=0.01)$ & Group 2< control group $(\mathrm{p}<0.01)$ \\
Sensorimotor & Group $1<$ control group $(\mathrm{p}=0.04)$ & Group $2=$ control group $(\mathrm{p}=0.10)$ \\
Visuospatial & Group $1=$ control group $(\mathrm{p}=0.14)$ & Group $2<\operatorname{control}$ group $(\mathrm{p}=0.02)$ \\
Memory and learning & Group $1=$ control group $(\mathrm{p}=0.61)$ & Group 2< control group $(\mathrm{p}<0.01)$
\end{tabular}

*Marlow refers to this group as 'severe NE.' This group is reclassified by one of the authors (MH) according to the classification system of Sarnat [50] 
Table 7 Verbal memory (Rey's Auditory Verbal Learning Test)* [31]

\begin{tabular}{ll}
\hline Age: 16 years & Moderate $\mathrm{NE}$ \\
\hline Total words learned trial $1-5$ & NE: $52.5, \mathrm{SD}=8.7$ \\
& Control group: $57, \mathrm{SD}=5.8$ \\
Delayed recall $(\mathrm{p}=0.034)$ & NE: $11.6, \mathrm{SD}=2.2$ \\
& Control group: $13.3, \mathrm{SD}=1.6$ \\
Recognition $(\mathrm{p}=0.011)$ & NE: $14.2, \mathrm{SD}=1.0$ \\
& Control group: $15, \mathrm{SD}=0.0$
\end{tabular}

*Raw scores (number correct)

prediction of the outcome of children with mild or severe $\mathrm{NE}$, in case of moderate NE this qualitative system lacks predictive power. Future research should therefore focus on developing a reliable, more gradual model of prediction.

Another issue regarding prediction of outcome after NE also mainly concerns moderately affected children. It is still unclear whether NE has a general effect on intellectual abilities or leads to specific patterns of cognitive strengths and difficulties. This review shows that systematic, detailed research of neuropsychological function is still scarce. A few case reports, which are not included in this review, have shown specific impairments in episodic memory (memory for events), with relatively intact semantic memory (memory for facts) [21, 58]. However, these findings, which were based on small numbers of children, do not justify generalization to all children with NE and should therefore be replicated in larger, well-defined samples.

The introduction section of this review referred to possible associations between brain areas that are vulnerable to perinatal hypoxia and psychopathology, such as ADHD and autism. Long-term behavioral outcome of survivors of NE has received very little attention compared to neurological outcome and general intellectual ability.

Table 8 Verbal memory (Children's auditory verbal learning test)* [47]

\begin{tabular}{ll}
\hline Age: 9 years & Moderate NE \\
\hline Level of learning $^{\mathrm{a}}$ & NE: $98, \mathrm{SD}=16$ \\
& Control group: $104, \mathrm{SD}=15$ \\
& NE: $96, \mathrm{SD}=18$ \\
Immediate recall $^{\mathrm{a}}$ & Control group: $105, \mathrm{SD}=15$ \\
& NE: $95, \mathrm{SD}=15$ \\
Delayed recall $^{\mathrm{a}}$ & Control group: $103, \mathrm{SD}=16$ \\
& NE: $22 \%$ delayed \\
Recognition accuracy & Control group: $27 \%$ delayed \\
& NE: $19 \%$ delayed \\
Total intrusions & Control group: $20 \%$ delayed \\
& NE: $97, \mathrm{SD}=15$ \\
Immediate attention & Control group: $100, \mathrm{SD}=15$ \\
\end{tabular}

* Mean of standardization sample $=100, \mathrm{SD}=15,{ }^{\mathrm{a}} \mathrm{p}<0.01 ;{ }^{\mathrm{b}}$ Delayed is below the $17^{\text {th }}$ percentile of the standardization sample
Only a few studies looked at the behavioral consequences of NE. Those studies found elevated rates of hyperactivity and autism in children with moderate NE. Evidence of hyperactivity and impulsive behavior has also been found in animal studies of PA $[1,60]$. These findings suggest that, in addition to cognitive impairment, children with NE could be at risk of developing behavioral problems. Because of the clinical implications this would have, future research should include behavioral monitoring of all children with NE.

Long-term follow-up of children with NE has been advocated before, including the optimal ages of assessment of specific functions [48]. Recommendations include assessment of general cognitive and adaptive behavioral functioning at preschool age, and, in some cases, school achievement tests and a neuropsychological screening at school age. The authors of this review would like to go one step further in recommending standard screening for behavioral problems in all children with NE, regardless of their level of cognitive functioning. In addition, detailed neuropsychological assessment is recommended especially in all children with moderate NE.

From this review it is concluded that general intellectual, educational and neuropsychological outcomes are consistently positive for children with mild NE and negative for severely affected children. However, children with moderate NE form a more heterogeneous group with respect to outcome. On average, intelligence scores are below those of children with mild NE and age-matched peers, but within the normal range. Difficulties have been found in the domains reading, spelling and arithmetic/mathematics. So far, neuropsychological functioning of children with NE has received relatively little attention. The studies that were selected for this review have yielded ambiguous results in children with moderate NE. A few studies suggest elevated rates of hyperactivity in children with moderate $\mathrm{NE}$ and autism in children with moderate and severe NE. Therefore, behavioral monitoring is required for all children with NE. In addition, systematic, detailed neuropsychological examination is needed especially for children with moderate NE.

Acknowledgement This research is supported by a grant of the Princess Beatrix Fund (MAR03-0122).

\section{References}

1. Adriani W, Giannakopoulou D, Bokulic Z, Jernej B, Alleva E, Laviola G (2006) Response to novelty, social and self-control behaviors, in rats exposed to neonatal anoxia: modulatory effects of an enriched environment. Psychopharmacology 184:155-165

2. Aggarwal P, Chaudhari S, Bhave S, Pandit A, Barve S (1998) Clinical predictors of outcome in hypoxic ischaemic encephalopathy in term neonates. Ann Trop Paediatr 18:117-121 
3. American Academy of Pediatrics CoFaN (1996) Use and abuse of the Apgar score. Pediatrics 98:141-142

4. American College of Obstetrics and Gynecology: Task force on Neonatal Encephalopathy (2003) Neonatal encephalopathy and cerebral palsy: Defining the pathogenesis and pathophysiology. American College of Obstetrics and Gynecology, Washington DC

5. Badawi N, Dixon G, Felix JF, Keogh JM, Petterson B, Stanley FJ, Kurinczuk JJ (2006) Autism following a history of newborn encephalopathy: more than a coincidence? Dev Med Child Neurol 48:85-89

6. Badawi N, Kurinczuk JJ, Keogh JM, Alessandri LM, O'Sullivan F, Burton PR, Pemberton PJ, Stanley FJ (1998) Intrapartum risk factors for newborn encephalopathy: the Western Australian casecontrol study. BMJ 317:1554-1558

7. Barkovich AJ (1992) MR and CT evaluation of profound neonatal and infantile asphyxia. Am J Neuroradiol 13:959-972

8. Barnett A, Mercuri E, Rutherford M, Haataja L, Frisone MF, Henderson S, Cowan F, Dubowitz L (2002) Neurological and perceptual-motor outcome at 5-6 years of age in children with neonatal encephalopathy: relationship with neonatal brain MRI. Neuropediatrics 33:242-248

9. Barnett AL, Guzzetta A, Mercuri E, Henderson SE, Haataja L, Cowan F, Dubowitz L (2004) Can the Griffiths scales predict neuromotor and perceptual-motor impairment in term infants with neonatal encephalopathy? Arch Dis Child 89:637-643

10. Blair E, Stanley FJ (1988) Intrapartum asphyxia-a rare cause of cerebral palsy. J Pediatr 112:515-519

11. Caravale B, Allemand F, Libenson MH (2003) Factors predictive of seizures and neurologic outcome in perinatal depression. Pediatr Neurol 29:18-25

12. Carli G, Reiger I, Evans N (2004) One-year neurodevelopmental outcome after moderate newborn hypoxic ischaemic encephalopathy. J Paediatr Child Health 40:217-220

13. Cowan F (2000) Outcome after intrapartum asphyxia in term infants. Semin Neonatol 5:127-140

14. de Haan M, Wyatt JS, Roth S, Vargha-Khadem F, Gadian D, Mishkin M (2006) Brain and cognitive-behavioural development after asphyxia at term birth. Dev Sci 9(4):350-358

15. DeLong GR (1992) Autism, amnesia, hippocampus, and learning. Neurosci Biobehav Rev 16:63-70

16. Dilenge ME, Majnemer A, Shevell MI (2001) Long-term developmental outcome of asphyxiated term neonates. J Child Neurol 16:781-792

17. Dixon G, Badawi N, Kurinczuk JJ, Keogh JM, Silburn SR, Zubrick SR, Stanley FJ (2002) Early developmental outcomes after newborn encephalopathy. Pediatrics 109:26-33

18. Ellis M, Manandhar N, Shrestha PS, Shrestha L, Manandhar DS, Costello AM (1999) Outcome at 1 year of neonatal encephalopathy in Kathmandu, Nepal. Dev Med Child Neurol 41:689-695

19. Ferriero D (2004) Neonatal brain injury. N Engl J Med 351:19851995

20. Freeman JM, Nelson KB (1988) Intrapartum asphyxia and cerebral palsy. Pediatrics 82(2):240-249

21. Gadian DG, Aicardi J, Watkins KE, Porter DA, Mishkin M, Vargha-Khadem F (2000) Developmental amnesia associated with early hypoxic-ischaemic injury. Brain 123:499-507

22. Gluckman PD, Wyatt JS, Azzopardi D, Edwards AD, Ballard R, Ferriero DM, Polin RA, Robertson CM, Thoresen M, Whitelaw A, Gunn AJ (2005) Selective head cooling with mild systemic hypothermia after neonatal encephalopathy: Multicentre randomised trial. Lancet 365:663-670

23. Gonzalez FF, Miller SP (2006) Does perinatal asphyxia impair cognitive function without cerebral palsy? Arch Dis Child 91: F454-F459

24. Gray PH, Tudehope DI, Masel JP, Burns YR, Mohay HA, O'Callaghan MJ, Williams GM (1993) Perinatal hypoxic-ischae- mic brain injury: prediction of outcome. Dev Med Child Neurol 35:965-973

25. Hankins GD, Speer M (2003) Defining the pathogenesis and pathophysiology of neonatal encephalopathy and cerebral palsy. Obstet Gynecol 102:628-636

26. Ilves P, Lintrop M, Metsvaht T, Vaher U, Talvik T (2004) Cerebral blood-flow velocities in predicting outcome of asphyxiated newborn infants. Acta Paediatr 93:523-528

27. Leviton A, Nelson KB (1992) Problems with definitions and classifications of newborn encephalopathy. Pediatric Neurology 8:85-90

28. Lou HC (1996) Etiology and pathogenesis of attention-deficit hyperactivity disorder (ADHD): significance of prematurity and perinatal hypoxic-haemodynamic encephalopathy. Acta Paediatr 85:1266-1271

29. Low JA, Galbraith RS, Muir DW, Killen HL, Pater EA, Karchmar EJ (1988) Motor and cognitive deficits after intrapartum asphyxia in the mature fetus. Am J Obstet Gynecol 158(2):356-361

30. MacLennan A (1999) A template for defining a causal relation between acute intrapartum events and cerebral palsy: international consensus statement. BMJ 319:1054-1059

31. Maneru C, Serra-Grabulosa JM, Junque C, Salgado-Pineda P, Bargallo N, Olondo M, Botet-Mussons F, Tallada M, Mercader JM (2003) Residual hippocampal atrophy in asphyxiated term neonates. J Neuroimaging 13(1):68-74

32. Marlow N, Rose AS, Rands CE, Draper ES (2005) Neuropsychological and educational problems at school age associated with neonatal encephalopathy. Arch Dis Child Fetal Neonatal Ed 90: F380-F387

33. Miller SP, Latal B, Barnwell A, Barkovich AJ, Ferriero DM, Clark H, Partridge JC, Glidden D (2004) Clinical signs predict 30-month neurodevelopmental outcome after neonatal encephalopathy. Am J Obst Gyn 190:93-99

34. Miller SP, Ramaswamy V, Michelson D, Barkovich AJ, Holshouser B, Wycliffe N, Glidden DV, Deming D, Partridge JC, Wu YW, Ashwal S, Ferriero DM (2005) Patterns of brain injury in term neonatal encephalopathy. J Pediatr 146:453-460

35. Moster D, Lie RT, Markestad T (2002) Joint association of Apgar scores and early neonatal symptoms with minor disabilities at school age. Arch Dis Child Fetal Neonatal Ed 86:F16-F21

36. Nelson KB, Dambrosia JM, Ting TY, Grether JK (1996) Uncertain value of electronic fetal monitoring in predicting cerebral palsy. N Engl J Med 334:613-618

37. Nelson KB, Ellenberg JH (1981) Apgar scores as predictors of chronic neurologic disability. Pediatrics $68: 36-44$

38. Nelson KB, Leviton A (1991) How much of neonatal encephalopathy is due to birth asphyxia? Am J Dis Child 145:1325-1331

39. Oygür N, Sőnmez O, Saka O, Yeğin O (1998) Predictive value of plasma and cerebrospinal fluid tumour necrosis factor-alpha and interleukin-1 beta concentrations on outcome of full term infants with hypoxic-ischaemic encephalopathy. Arch Dis Child Fetal Neonatal Ed 79:F190-F193

40. Painter MJ, Scott M, Hirsch RP, O’Donoghue P, Depp R (1988) Fetal heart rate patterns during labor: neurologic and cognitive development at six to nine years of age. Am J Obstet Gynecol 159 (4):854-858

41. Peliowski A, Finer N (1992) Birth asphyxia in the term infant. In: Sinclair JC, Bracken MB (eds) Effective care of the newborn infant. Oxford University Press, Oxford, pp 249-280

42. Rademakers RP, van der Knaap MS, Verbeeten B Jr, Barth PG, Valk J (1995) Central cortico-subcortical involvement: a distinct pattern of brain damage caused by perinatal and postnatal asphyxia in term infants. J Comput Assist Tomogr 19:256-263

43. Robertson CM, Finer NN (1985) Term infants with hypoxicischemic encephalopathy: outcome at 3.5 years. Dev Med Child Neurol 27:473-484 
44. Robertson CM, Finer NN (1988) Educational readiness of survivors of neonatal encephalopathy associated with birth asphyxia at term. J Dev Behav Pediatr 9:298-306

45. Robertson CM, Finer NN (1993) Long-term follow-up of term neonates with perinatal asphyxia. Clin Perinatol 20:483-500

46. Robertson CM, Finer NN, Grace MG (1989) School performance of survivors of neonatal encephalopathy associated with birth asphyxia at term. J Pediatr 114:753-760

47. Robertson CM (1997) Long-term follow-up of term infants with perinatal asphyxia. In: Stevenson DK, Sunshine P (eds) Fetal and neonatal brain injury: mechanisms, management and the risks of practice, 2nd edn. Oxford University Press, Oxford, pp 615-630

48. Robertson CM, Perlman M (2006) Follow-up of the term infant after hypoxic-ischemic encephalopathy. Paediatric Child Health $11: 278-282$

49. Rutherford M, Pennock J, Schwieso J, Cowan F, Dubowitz L (1996) Hypoxic-ischaemic encephalopathy: early and late magnetic resonance imaging findings in relation to outcome. Arch Dis Child Fetal Neonatal Ed 75:F145-F151

50. Sarnat HB, Sarnat MS (1976) Neonatal encephalopathy following fetal distress. A clinical and electroencephalographic study. Arch Neurol 33:696-705

51. Seidman DS, Paz I, Laor A, Gale R, Stevenson DK, Danon YL (1991) Apgar scores and cognitive performance at 17 years of age. Obstet Gynecol 77(6):875-878

52. Shankaran S, Laptook AR, Ehrenkranz RA, Tyson JE, McDonald SA, Donovan EF, Fanaroff AA, Poole WK, Wright LL, Higgins RD, Finer NN, Carlo WA, Duara S, Oh W, Cotten CM, Stevenson DK, Stoll BJ, Lemons JA, Guillet R, Jobe AH (2005) Whole-body hypothermia for neonates with hypoxic-ischemic encephalopathy. N Engl J Med 353:1574-1584
53. Shankaran S, Woldt E, Koepke T, Bedard MP, Nandyal R (1991) Acute neonatal morbidity and long-term central nervous system sequelae of perinatal asphyxia in term infants. Early Hum Dev 25:135-148

54. Shevell MI, Majnemer A, Miller SP (1999) Neonatal neurologic prognostication: the asphyxiated term newborn. Pediatr Neurol 21:776-784

55. Thompson CM, Puterman AS, Linley LL, Hann FM, van der Elst CW, Molteno CD, Malan AF (1997) The value of a scoring system for hypoxic ischaemic encephalopathy in predicting neurodevelopmental outcome. Acta Paediatr 86: $757-761$

56. Toft PB (1999) Prenatal and perinatal striatal injury: a hypothetical cause of attention-deficit-hyperactivity disorder? Pediatr Neurol 21:602-610

57. Van Petten C (2004) Relationship between hippocampal volume and memory ability in healthy individuals across the lifespan: review and meta-analysis. Neuropsychologia 42 (10):1394-1413

58. Vargha-Khadem F, Gadian DG, Watkins KE, Connelly A, Van Paesschen W, Mishkin M (1997) Differential effects of early hippocampal pathology on episodic and semantic memory. Science 277:376-380

59. Volpe JJ (2001) Neurology of the newborn. Saunders, Philadelphia

60. Weitzdoerfer R, Pollak A, Lubec B (2004) Perinatal asphyxia in the rat has lifelong effects on morphology, cognitive functions, and behavior. Semin Perinatol 28:249-256

61. Yokochi K, Fujimoto S (1996) Magnetic resonance imaging in children with neonatal asphyxia: correlation with developmental sequelae. Acta Paediatr 85:88-95 